\title{
ASPECTS OF DRIFT AND DUCTILITY CAPACITY OF RECTANGULAR CANTILEVER STRUCTURAL WALLS
}

\author{
M.J.N. Priestley ${ }^{1,2}$ and M. J. Kowalsky ${ }^{1}$
}

\begin{abstract}
Moment-curvature analyses of cantilever shear walls are used to show that yield curvature, serviceability curvature, and ultimate (damage-control) curvature are insensitive to variations of axial load ratio, longitudinal reinforcement ratio, and distribution of longitudinal reinforcement. The results are used to determine available displacement ductility factors for walls of different aspect ratios and drift limits. It is shown that drift capacity will generally exceed code levels of permissible drift, and that code drift limits will normally restrict, sometimes severely, the design displacement ductility factor.
\end{abstract}

\section{INTRODUCTION}

A fundamental basis of force-based seismic design of reinforced concrete structures has been the assumption that the stiffness of members can be directly related to gross section sizes. Until comparatively recently, gross section dimensions were used to determine member stiffness, and strengths were apportioned between elements in proportion to stiffness. More recently, it has been common to make some allowance for cracking in reducing the effective moment of inertia of reinforced concrete members. For example, Paulay and Priestley [1] recommend values for columns that vary between $0.4 I_{g}$ and $0.8 I_{g}$ depending on axial load level. Similarly, values of $0.3 I_{g}$ to $0.5 I_{g}$ are often assumed for walls.

However, the approach of allocating strength to members in proportion to their assumed stiffness commonly leads to significant errors, regardless as to whether gross stiffness or some fraction of gross stiffness is assumed. As pointed out in an earlier paper [2] use of modal analysis to determine design forces in columns of a frame requires that the influence of seismic axial load on columns be ignored when determining stiffness. This results in columns subjected to seismic axial tension being critical for design, since the axial tension is considered in strength, but not stiffness calculations. In fact, the columns subjected to axial compression will be more critical in terms of damage potential, typically reaching serviceability or damage control limit states earlier than the tension-dominated column, and if stiffness is correctly modeled, reinforcement for the tension and compression columns will turn out to be very nearly the same.

This is illustrated in Fig. 1, where the consequences of current design approximations are shown in Fig. 1(a), with 'realistic' conditions shown in Fig. 1(b). In current design, it is assumed that the stiffness is a fundamental property of the section. Thus the yield curvature of a section is directly proportional to the yield moment, as shown in Fig. 1(a). In fact, if the strength of the section is altered by changes in axial load ratio or flexural reinforcement content, the stiffness and strength vary essentially in proportion, as shown in Fig. 1(b). This implies that the yield curvature, not the section stiffness, should be considered the fundamental section property. Extensive analyses of bridge columns [3] have shown that over a range of axial loads of $0 \leq N / f^{\prime}{ }_{C} A g \leq$ 0.4 and longitudinal steel ratio $0.01 \leq \rho_{l}=A_{s t} / A_{g} \leq 0.04$, the yield curvature can be expressed as

circular column: $\phi_{y} D=2.45 \varepsilon_{y} \pm 15 \%$

rectangular column: $\phi_{y} h=2.14 \varepsilon_{y} \pm 10 \%$

where $\phi_{y}$ is the yield curvature of the equivalent bilinear approximation to the moment curvature relationship, $D$ and $h$ are the diameter and section depth of circular and rectangular columns respectively, and $\varepsilon_{y}=f_{y} / E_{S}$ is the yield strain of the longitudinal reinforcement. The relationship of Eqn. 1 should not be extrapolated beyond the range $300 \leq f_{y} \leq 500$ $\mathrm{MPa}$ nor beyond the limits of longitudinal steel ratio and axial load ratio considered.

\section{LIMIT STATE CURVATURE FOR WALLS}

The comparative insensitivity of column yield curvature to variation in axial load and longitudinal reinforcement ratios indicates that walls might reasonably be expected to follow similar trends. To investigate this, rectangular walls with different axial load ratios, longitudinal reinforcement ratios, and reinforcement patterns were analyzed to determine trends in their moment-curvature relationships. As well as yield curvature, curvatures at the serviceability and damage control

\footnotetext{
1 Structural Systems Research Group, University of California, San Diego

2 Fellow
} 
limit states were of interest. For this study the following definitions were adopted:

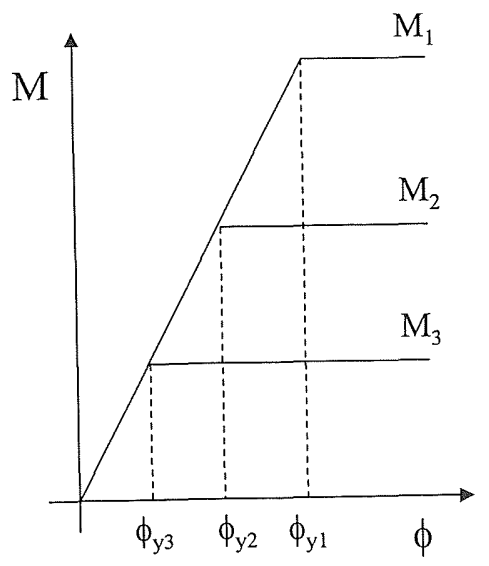

(a) Design assumption (constant stiffness)

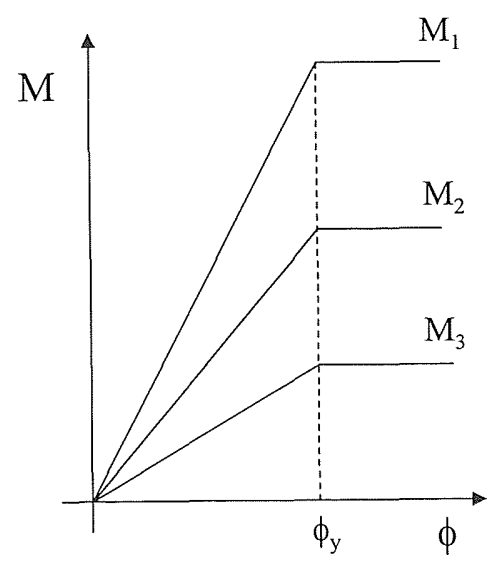

(b) Realistic conditions (constant yield curvature)

\section{FIGURE 1 Influence of strength on moment- curvature relationship}

Yield curvature $\phi y$ was defined as the curvature found by extrapolating the line from the origin of the momentcurvature curve through first yield $\left(M_{y}, \phi^{\prime} y\right)$ to the nominal flexural strength $M_{n}$ corresponding to the moment at 5 times yield curvature (See Fig. 2). For a wall with high axial load and high reinforcement content this typically corresponds to an extreme fiber compression strain of about 0.003 to 0.004 . For lower axial loads and reinforcement ratios, lower extreme fiber compression strains were appropriate. This definition avoided the possibility of excessive strain hardening influencing the yield moment and curvature, since the full stress-strain curve for the reinforcement was utilized in the analyses.
Thus

$$
\phi_{y}=\phi_{y}^{\prime} M_{n} / M_{y}
$$

In eq. 2, first yield is defined as the moment and curvature corresponding to $\varepsilon_{\mathrm{s}}=f_{y} / E_{\mathrm{s}}$ or $\varepsilon_{\mathrm{c}}=0.002$, whichever occurs first.

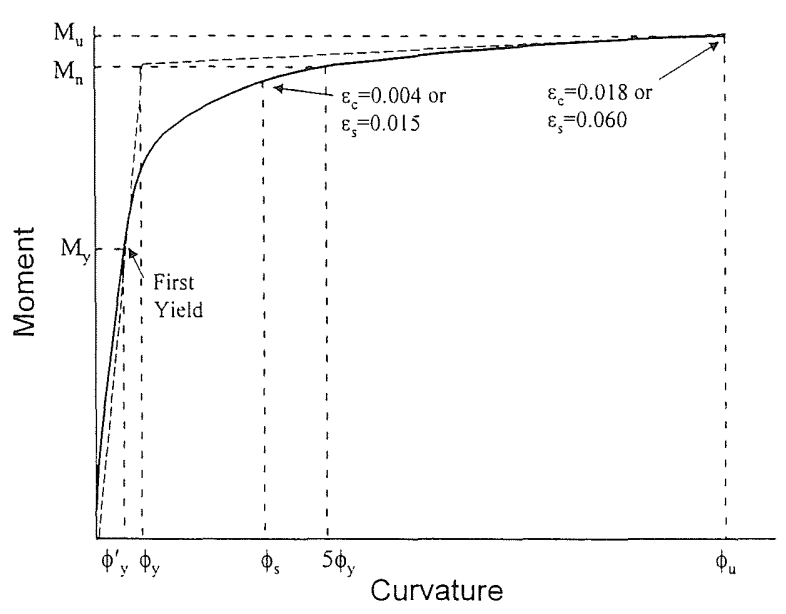

\section{FIGURE 2 Moment-curvature relationship for rectangular wall and limit state definitions}

Serviceability curvature $\phi_{S}$ was defined as the lower of the curvatures corresponding to $\varepsilon_{\mathrm{C}}=0.004$ and $\varepsilon_{\mathrm{S}}=0.015$. These strains are reasonably conservative estimates of values corresponding to onset of incipient spalling, and the steel strain resulting in residual crack widths greater than $1.0 \mathrm{~mm}$ [3]. Beyond either of these limit strains repair might be needed, interrupting serviceability of the structure.

Note that this definition of serviceability does not conform to the definition of NZS4203 [4] and NZS3101 [5] which define serviceability as the state corresponding to the yield displacement (or yield curvature) -- i.e., a displacement ductility of $\mu=1.0$. Clearly this does not actually represent true serviceability, and has been adopted primarily as a matter of convenience. Unfortunately, it results in nonuniform protection against actual onset of damage, since the displacement ductility at a given limit state is a function of building geometry, as well as limit state curvature [1].

Damage control or 'ultimate' curvature $\phi_{u}$ was defined as the lower of the curvatures corresponding to $\varepsilon_{\mathrm{C}}=0.018$ and $\varepsilon_{\mathrm{S}}=0.06$. These are reasonably conservative estimates of damage-control limit strains for well-confined concrete and well-restrained reinforcement as results from detailing to the requirements of NZS3101 [5]. Significantly higher strains $[30-50 \%$ higher $]$ are expected at the survival limit state. 
The analyses were based on a $4 \mathrm{~m}$ long wall $250 \mathrm{~mm}$ wide, with $f_{c}^{\prime}=27.5 \mathrm{MPa}$ and $f_{y}=450 \mathrm{MPa}$. Results were then generalized into non-dimensional formats to apply to walls of different geometry and material strengths. The axial load compression stress was varied in the range $0 \leq N / A_{g} \leq 3.0$ $\mathrm{MPa}$ corresponding to an axial load ratio of $0 \leq N / f^{\prime} c^{A} A_{g} \leq$ 0.11. The upper level of load would be appropriate for a twelve-story boundary wall. The computer program used for the studies [6] included effects of steel strain hardening and confinement of concrete.

Longitudinal reinforcement ratio was varied between $0.25 \%$ and $2.0 \%$. Initially, for simplicity, all reinforcement was considered to be distributed uniformly along the wall length. A second set of analyses was then carried out with a $0.5 \%$ reinforcement ratio distributed uniformly along the wall length with the balance of reinforcement (up to $1.5 \%$ ) concentrated in two equal groups at a distance of $0.04 \ell_{\mathrm{W}}$ from each end of the wall.

\section{RESULTS OF THE ANALYSES}

\subsection{Yield Curvature}

Results of the analyses can be expressed in the dimensionless form

$$
\phi_{\mathrm{y}} \ell_{\mathrm{w}}=\mathrm{K}_{1} \varepsilon_{\mathrm{y}}
$$

previously adopted for columns [3]. Figs. 3(a) and 3(b) show the variations of $\mathrm{K}_{1}$, with axial load ratio and longitudinal reinforcement ratio for walls with uniformly distributed, and with concentrated end reinforcement, as described above. The results are found to be comparatively insensitive to the range of the variables considered. In Fig. 3(a) (distributed reinforcement) it can be seen that, if we exclude the data for $\rho 1$

$=0.0025$ (code minimum), the dimensionless yield curvature can be expressed as

\section{distributed reinforcement:}

$$
\phi_{\mathrm{y}} \ell_{\mathrm{w}}=2.25 \varepsilon_{\mathrm{y}} \pm 15 \%
$$

For most of the useful range the agreement is better than $\pm 10 \%$. For $0.5 \%$ distributed plus concentrated end steel (Fig. $3(b)$ ), the curvatures are approximately $10 \%$ lower, and the scatter is considerably less. For these analyses, excluding only the data for low axial load together with low reinforcement ratio, the dimensionless yield curvature can be expressed as

\section{$0.5 \%$ distributed plus end reinforcement:}

$$
\phi_{\mathrm{y}} \ell_{\mathrm{w}}=2.0 \varepsilon_{\mathrm{y}} \pm 5 \%
$$

It would be reasonable to use Eqn. 4(b) for both categories of walls, since the higher values of $K_{1}$ in Fig. 3(a) compared to the somewhat unrealistic case of high reinforcement ratios uniformly distributed along the wall length. Note that the yield curvature values of Eqn. 4 are somewhat larger than recently suggested by Paulay [7].

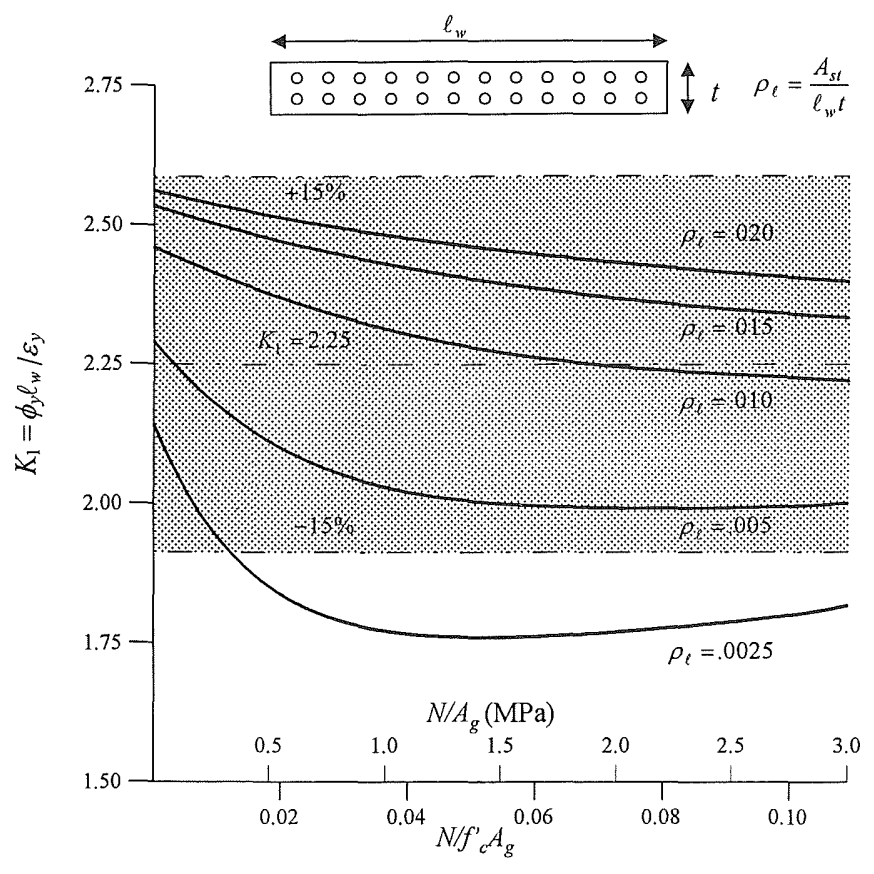

(a) Distributed reinforcement

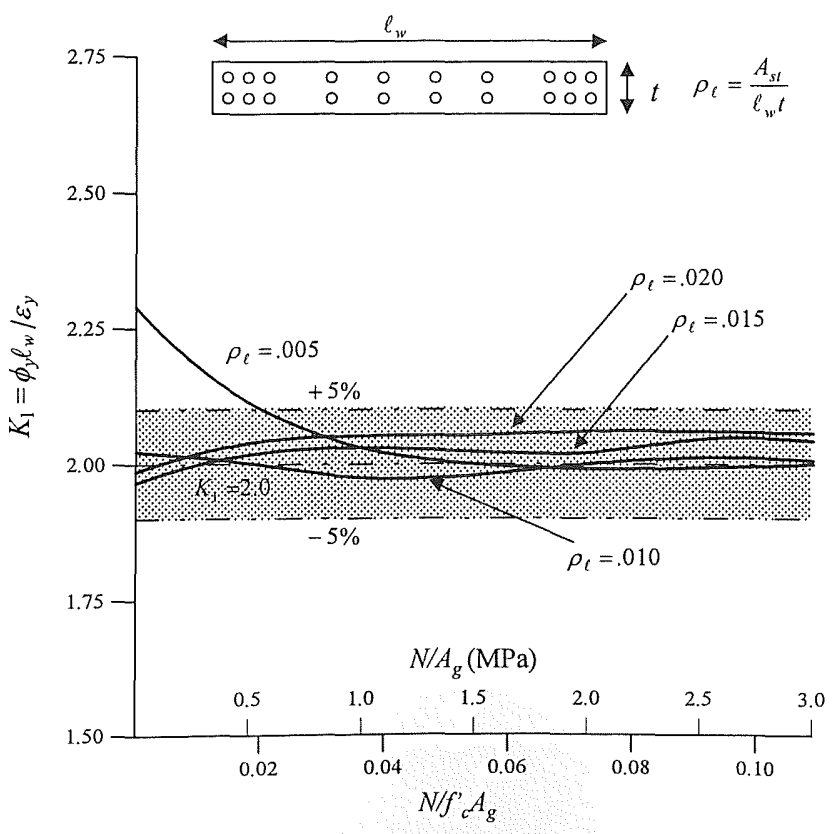

(b) Concentrated reinforcement

\section{FIGURE 3 Dimensionless yield curvature for structural wall}




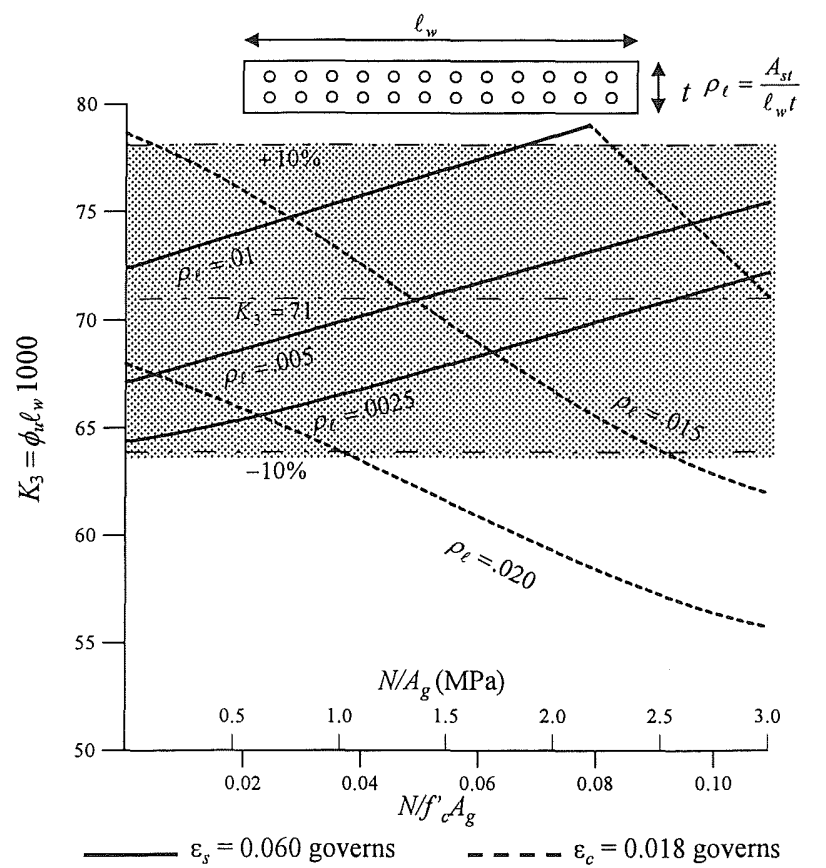

(a) Distributed reinforcement

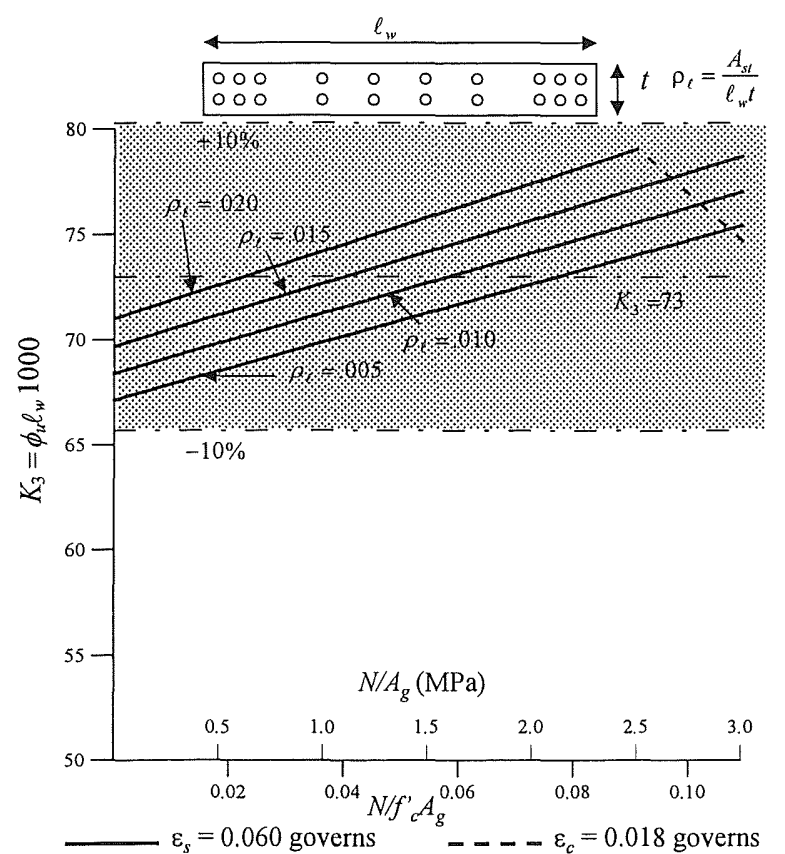

(b) Concentrated reinforcement

\section{FIGURE 5 Dimensionless ultimate curvature of structural wall}

This implies that yield deflection is also independent of axial load and reinforcement content and can be expressed in the form

$$
\Delta_{y}=\left(\frac{K_{1} \varepsilon_{y}}{\ell_{w}}\right) \frac{h_{e}^{2}}{3}
$$

where $K_{1}$ is given by Fig. 3 or Eqn 4 , and $h_{e}$ is the effective wall height measured to the center of seismic lateral force $\left(h_{e}\right.$ $\approx(2 / 3) h_{w}$, where $h_{w}$ is the total wall height). Thus it is not necessary to know the wall strength to know its yield displacement.

The results of Fig. 3 also indicate that, if the building contains walls of different length in the same direction it will be impossible for these walls to have the same yield displacement, since Eqn. 8 indicates the yield displacement is inversely proportional to wall length. This means that the basic presumption of current design, that allocating strength to walls in proportion to their stiffnesses as a means to obtain simultaneous yield of the walls, and hence uniform ductility demand, is impossible to achieve.

It might be felt that the data of Fig. 3 might be used in a refined stiffness approach where the stiffness is modified to represent the actual axial load and reinforcement ratio in a successive approximation approach. In fact this will result in worse results than if the simple stiffness approach currently adopted is used, since it will inevitably attract extra force to stiffer walls, resulting in higher reinforcement ratios for these walls which further increases their stiffness relative to more flexible walls. The end result is that the more flexible walls become nominally reinforced.

The answer, as has been suggested by Paulay [7], is to apportion lateral force between walls essentially in proportion to $\ell_{\mathrm{W}}{ }^{2}$, rather than the $\ell_{\mathrm{W}}{ }^{3}$, as would result from a stiffness approach. For walls with similar axial load ratios this will result in a demand for essentially constant reinforcement ratios in all the walls.

\subsection{Ductility Capacity}

Since Figs. 3-5 indicate that yield, serviceability, and ultimate curvatures can all be expressed as constant values, the curvature ductility factors corresponding to a given limit state may also be considered constant. Thus, from Eqns. $4(\mathrm{~b}), 6(\mathrm{a})$, and $7(\mathrm{a})$, serviceability $\left(\mu_{\phi \mathrm{s}}\right)$ and ultimate curvature ductility $\left(\mu_{\phi u}\right)$ factors may be expressed as

$$
\begin{aligned}
& \mu_{\phi_{s}}=\frac{0.0174}{2 \varepsilon_{y}} \\
& \mu_{\phi_{n}}=\frac{0.072}{2 \varepsilon_{y}}
\end{aligned}
$$

For $f_{y}=450 \mathrm{MPa}, \varepsilon_{\mathrm{y}}=0.00225$, Eqns. 9 and 10 simplify to $\mu_{\phi \mathrm{S}}=3.87$ and $\mu_{\phi \mathrm{u}}=16$ respectively. For $f_{y}=300 \mathrm{MPa}$, the values would be $\mu_{\phi \mathrm{s}}=5.8$ and $\mu_{\phi \mathrm{u}}=24$ respectively.

These values can be used to estimate the displacement ductility factors corresponding to the two limit states. Paulay and Priestley [1] suggest two alternate expressions for the plastic hinge length:

$$
\ell_{p}=0.2 \ell_{w}+0.044 h_{e}
$$




$$
\ell_{p}=0.08 h_{e}+0.022 f_{y} d_{b l}
$$

Equation 11 includes $\ell_{w}$ in the estimate of plastic hinge to account for the influence of plasticity spread due to diagonal cracking. It is felt to be more appropriate for squat walls. Equation 12, which was originally developed for columns, is more strongly related to effective wall height $h_{e}$, and includes a term for strain penetration into the foundation, which is dependent on the diameter $d_{b l}$ and yield strength $f_{y}$ of the longitudinal reinforcement, and should be more appropriate at higher aspect ratios. The two expressions are plotted in the dimensionless form $\ell_{p} / h_{e}$ against wall aspect ratio $h_{e} / \ell_{w}$ in Fig. 6. Axes based on full wall height $h_{w}\left[h_{e}\right.$ $=0.67 h_{w}$ ] are also included for convenience. In Fig. 6, two curves are given for Eqn. 12, based on $\ell_{w}=3 \mathrm{~m}$ and $\ell_{w}=6$ $\mathrm{m}$ respectively. In both cases $d_{b}=24 \mathrm{~mm}$ was assumed.

Displacement ductility capacity, $\mu_{\Delta}$, can be related to curvature ductility capacity $\mu_{\phi}$ by the expression [1]:

$$
\mu_{\Delta}=1+3\left(\mu_{\phi}-1\right) \frac{\ell_{p}}{h_{e}}\left(1-\frac{\ell_{p}}{2 h_{e}}\right)
$$

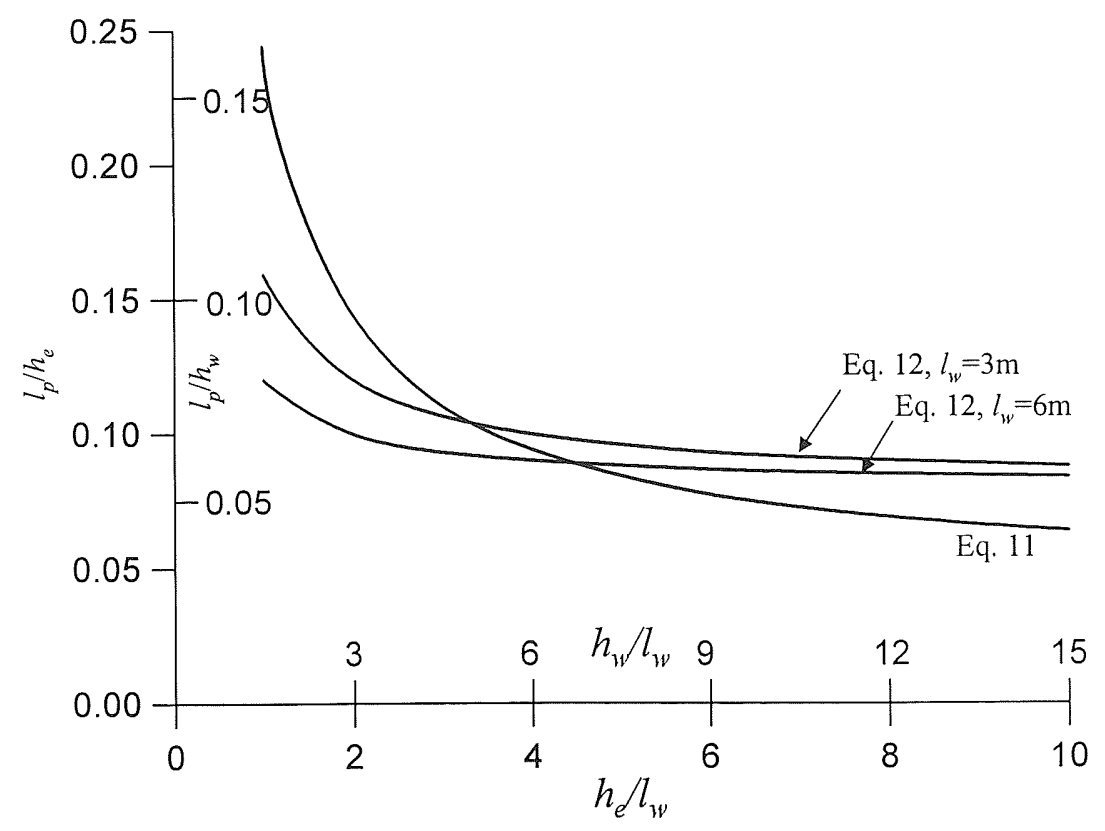

FIGURE 6 Plastic hinge length as a function of aspect ratio, $f_{y}=450 \mathrm{MPa}\left(h_{w}=\right.$ full wall height, $\left.h_{e}=(2 / 3) h_{w}\right)$

Fig. 7 plots the available serviceability and ultimate displacement ductility factors for walls reinforced longitudinally with $f_{y}=450 \mathrm{MPa}$ reinforcement, based on Eqn. 13 and the ratios $\ell_{p} / h_{e}$ given in Fig. 6. It is suggested that the higher of Eqn. 11, and of Eqn. 12 with $\ell_{w}=6 \mathrm{~m}$, be taken as a reasonable estimate of ductility capacity, identified in Fig. 7 by the hatched boundary. For the serviceability limit state this results in displacement ductilities reducing from more than 2.0 for low wall aspect ratios to about 1.6 for slender walls. The ultimate limit state corresponds to displacement ductilities as high as 10 for squat walls, and about 4.3 for slender walls, which is in reasonable agreement with the values defined in NZS3101 $\left(\mu_{\Delta}=5\right.$ for slender walls), though the decrease at low aspect ratios in the NZS3101 equation, which is intended to compensate for wall slip on the base and reduced energy absorption, is opposite to the predicted trend for theoretical ductility capacity.

It should be noted that the ductility capacities in Fig. 7 are for a probable yield strength of $f_{y}=450 \mathrm{MPa}$. Using a lower specified strength will correspondingly increase the ductility capacities. For example, using $f_{y}=300 \mathrm{MPa}$ increases the lower bound for serviceability and ultimate displacement ductilities to $\mu_{\Delta s}=2.0$ and $\mu_{\Delta u}=6.0$ respectively. It would seem reasonable to reflect the greater ductility capacity of walls reinforced with lower yield strength reinforcement in code design approaches.

\subsection{Drift ratios}

The data presented in Figs. 3-5 also allow estimates of drift capacity to be made. Conservatively assuming a linear curvature distribution from the maximum $f y$ of the wall base to zero at the wall top to allow for tension shift, the distribution of displacement with height $h \leq h_{w}$, corresponding to 'yield' conditions can be approximated by

$$
\Delta_{e(h)}=\frac{\phi_{y} h^{2}}{3}\left(1.5-\frac{h}{2 h_{w}}\right)
$$

Substituting $\phi_{y}=2 \varepsilon_{y} / \ell_{w}$ from Eqn. 4,

$$
\Delta_{e(h)}=\frac{2}{3} \frac{\varepsilon_{y} h^{2}}{\ell_{w}}\left(1.5-\frac{h}{2 h_{w}}\right)
$$


Differentiating to get the drift angle (i.e., $\theta_{\mathrm{e}}=\mathrm{d} \Delta / \mathrm{d} h$ ), and evaluating for the maximum at $h=h_{w}$

$$
\theta_{e_{\text {mux }}}=\varepsilon_{y}\left[\frac{h_{w}}{\ell_{w}}\right]=\varepsilon_{y} A_{w}
$$

where $A_{w}=h_{w} \ell_{w}$ is the aspect ratio related to the full wall height.

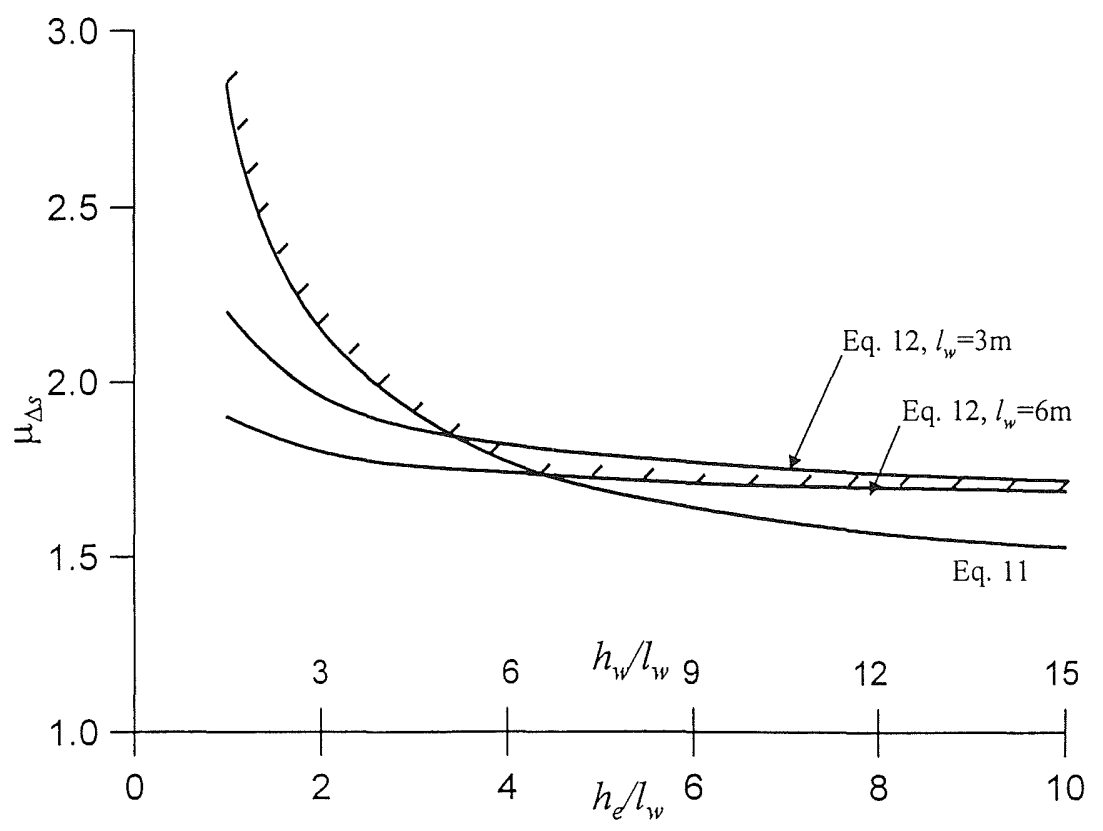

(a) Serviceability limit state $\left(\mu_{\phi s}=3.87\right)$

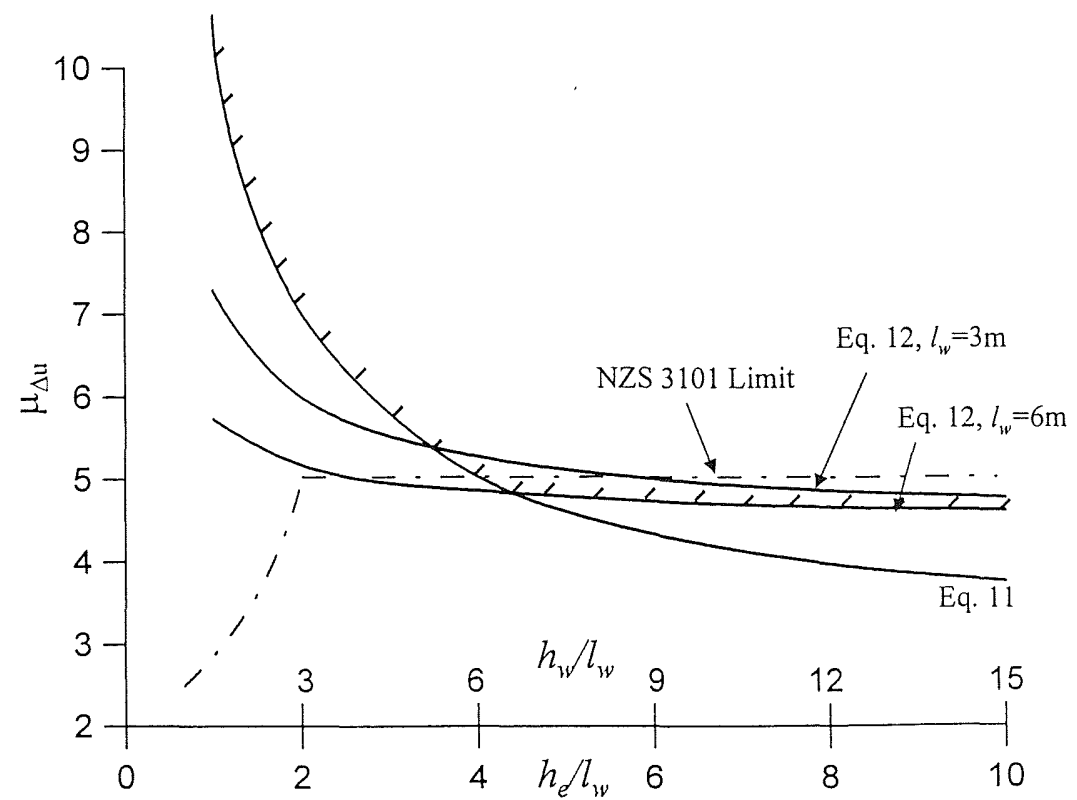

(b) Ultimate limit state $\left(\mu_{\phi s}=16\right)$

FIGURE 7 Displacement ductility capacity for walls of different aspect ratios 

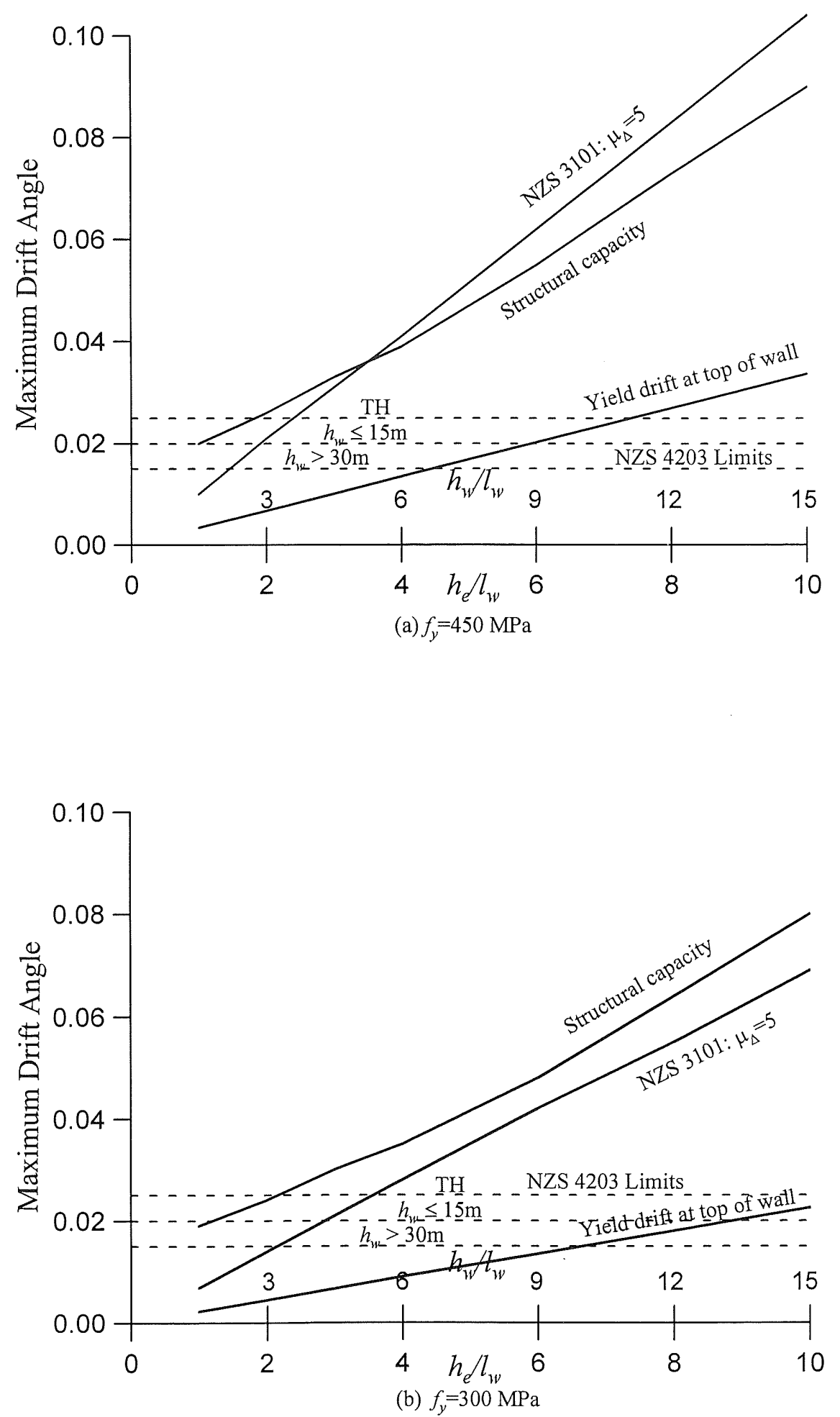

FIGURE 8 Maximum drift at structural ductility capacity related to aspect ratio 
Substituting from Eqns. 4 and 6

$$
\theta_{p}=\left(0.072-2 \varepsilon_{y}\right) \frac{\ell_{p}}{\ell_{w}}
$$

Putting $\varepsilon_{\mathrm{y}}=0.00225$ (for $f_{y}=450 \mathrm{MPa}$ ), and rearranging, Eqn. 17 becomes

$$
\theta_{p}=0.0675\left(\frac{\ell_{p}}{h_{e}}\right)\left(\frac{h_{c}}{\ell_{w}}\right)
$$

Taking $\ell_{p} / h_{e}$ from Fig. 6 and summing the results from Eqns. 15 and 18, enables the total maximum drift, (top storey) corresponding to the ultimate limit state to be plotted as a function of aspect ratio, as shown in Fig. 8. The total maximum drift is also plotted based on the NZS3101 [5] ductility capacity of 5 . Shown as dotted lines in Fig. 8 are the NZS4203 [4] drift limits. The upper limit of 0.025 is only permitted when the predicted drift results from inelastic timehistory analysis, and that $\theta \leq 0.02$ (dependent on wall height) required when drift is assessed from equivalent static, or modal analyses. Fig. 8 is plotted for $f_{y}=300 \mathrm{MPa}$ as well as for $f_{y}=450 \mathrm{MPa}$. This requires putting $\varepsilon_{\mathrm{y}}=0.0015$ in Eqns. 15 and 17.

If design is performed using dynamic inelastic time history analysis and high strength reinforcement, it will be seen from Fig. 8a that the full structural ductility capacity will only be able to be utilized if the true wall aspect ratio is less than about $h_{w} / \ell_{w}=2.7$. Using the code ductility capacity of $\mu_{\Delta}=$ 5 , slightly more slender walls (about $h_{w} / \ell_{w}=3.5$ ) can be used before drift limits the permissible displacement ductility to less than the code value of $\mu_{\Delta}=5$. If equivalent static or modal analysis are employed, and the lower drift limitations imposed, then the full structural ductility capacity could be utilized only when the true wall aspect ratio is less than 1 for walls equal to or less than $15 \mathrm{~m}$ tall, and corresponding squater aspect ratios for walls greater than $30 \mathrm{~m}$ tall. For walls reinforced with longitudinal reinforcement of $f_{y}=300 \mathrm{MPa}$ (fig. 8b), the critical aspect ratios are less severe, though still onerous.

Also plotted in Fig. 8 is the maximum drift corresponding to the elastic curvature of Eqn. 4(b), based on Eqn. 15. It is seen that if the wall aspect ratio $h_{w} / \ell_{w}$ exceeds 11.25 for $f_{y}=$ $450 \mathrm{MPa}$ and 16.5 for $f_{y}=300 \mathrm{MPa}$ (after extrapolation), the elastic drift will exceed the code ultimate limit of 0.025 , and hence the full strength of the wall will not be able to be utilized. If equivalent static or modal analysis is employed, then the elastic drift will exceed the code limit of 0.02 for walls less than or equal to $15 \mathrm{~m}$ tall for aspect ratios greater than $9\left(f_{y}=450 \mathrm{MPa}\right)$ and greater than $13.5\left(f_{y}=300 \mathrm{MPa}\right)$. For walls greater than $30 \mathrm{~m}$ tall, the elastic drift will exceed the code limit of 0.015 when the wall aspect ratio is greater than $6.5\left(f_{y}=450 \mathrm{MPa}\right)$ and greater than $10\left(f_{y}=300 \mathrm{MPa}\right)$.

The maximum ductility capacity that can be used for a given wall, corresponding to the code drift limits of $\theta_{c}=0.025$, 0.02 and 0.015 can be found by subtracting the elastic drift to obtain the plastic drift $\theta_{p}$ and hence the plastic displacement $\Delta_{p}$ from

$$
\begin{aligned}
& \theta_{p}=\theta_{c}-\varepsilon_{y} A_{w} \\
& \Delta_{p}=\theta_{p}\left(h_{e}-\frac{\ell_{p}}{2}\right)
\end{aligned}
$$

and solving for the displacement ductility corresponding to $\Delta_{p}$ as

$$
\mu_{\Delta}=1+\frac{\Delta_{p}}{\Delta_{y}}
$$

where $\Delta_{y}$ is calculated from Eqn. 14, equivalent at $h=h_{e}$.

This is plotted in Figs. 9 through 11 for each of the three drift limits discussed for $f_{y}=450 \mathrm{MPa}$ and $300 \mathrm{MPa}$ in each case. Since NZS3101 restricts the displacement ductility to $\mu_{\Delta}<5$ for $h_{w} / \ell_{w}<2.7$, and the drift limit of 0.025 restricts the displacement ductility to $\mu_{\Delta}<5$ for $h_{w} / \ell_{w}>3.5$, it would appear that the code value of $\mu_{\Delta}=5$ will infrequently be achievable when higher reinforcing steel strengths are used. Furthermore, if design is performed utilizing equivalent static or modal analysis, then the code value of $\mu_{\Delta}=5$ will be achievable only for an aspect ratio of 3 for walls less than 15 $\mathrm{m}$ tall, and never for walls beyond $30 \mathrm{~m}$ tall. Even with lower strength $\left(f_{y}=300 \mathrm{MPa}\right)$ reinforcement, the range of walls for which the full code ductility level is applicable is severely restricted.

Finally, as Paulay [7] has pointed out, the fact that walls of different length will have yield displacements inversely proportional to the wall lengths means that shorter walls will not be able to develop their full displacement capacity before the longest wall reaches its limit displacement. Consequently, in structures with walls of varying length, the structure ductility capacity will be less than that of the longest wall. If walls are designed so that their strength is proportional to the square of the wall length (i.e, $V_{w} \propto \ell_{w}{ }^{2}$ ), then it can be shown that the available structure ductility capacity is given by

$$
\mu_{\Delta}=\mu_{\Delta_{r}} \frac{1}{\ell_{w_{r}}} \frac{\sum_{i=1}^{n} \ell_{w_{i}}^{3} \ell_{w_{i}}^{2}}{\sum_{i=1}^{n}}
$$

where $\ell_{w_{i}}$ is the length of the longest (reference) wall, and $\mu_{\Delta r}$ is the reference wall ductility factor.

\section{CONCLUSIONS}

1. Moment-curvature analysis of structural walls indicate that yield curvature, serviceability curvature and damage-control (ultimate) curvature are insensitive to axial load ratio, longitudinal reinforcement ratio and distribution of longitudinal reinforcement. As a 


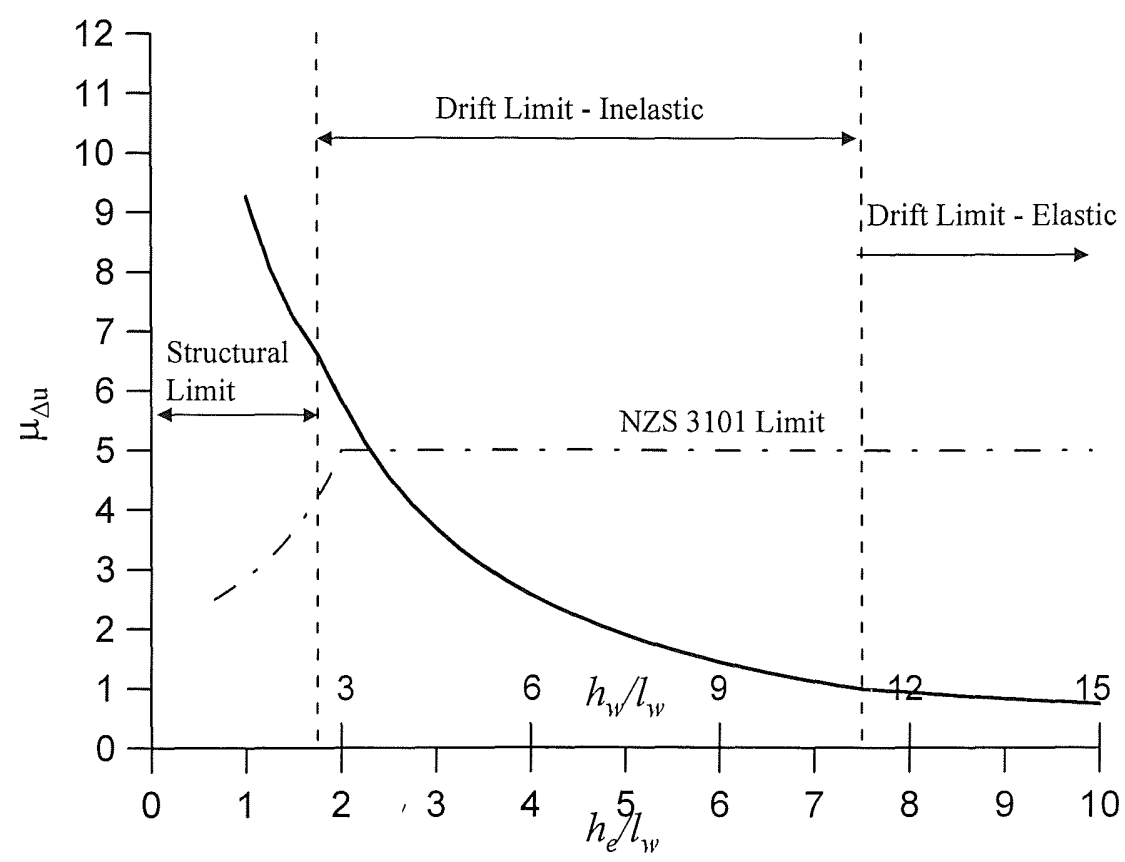

(a) $f_{y}=450 \mathrm{MPa}$

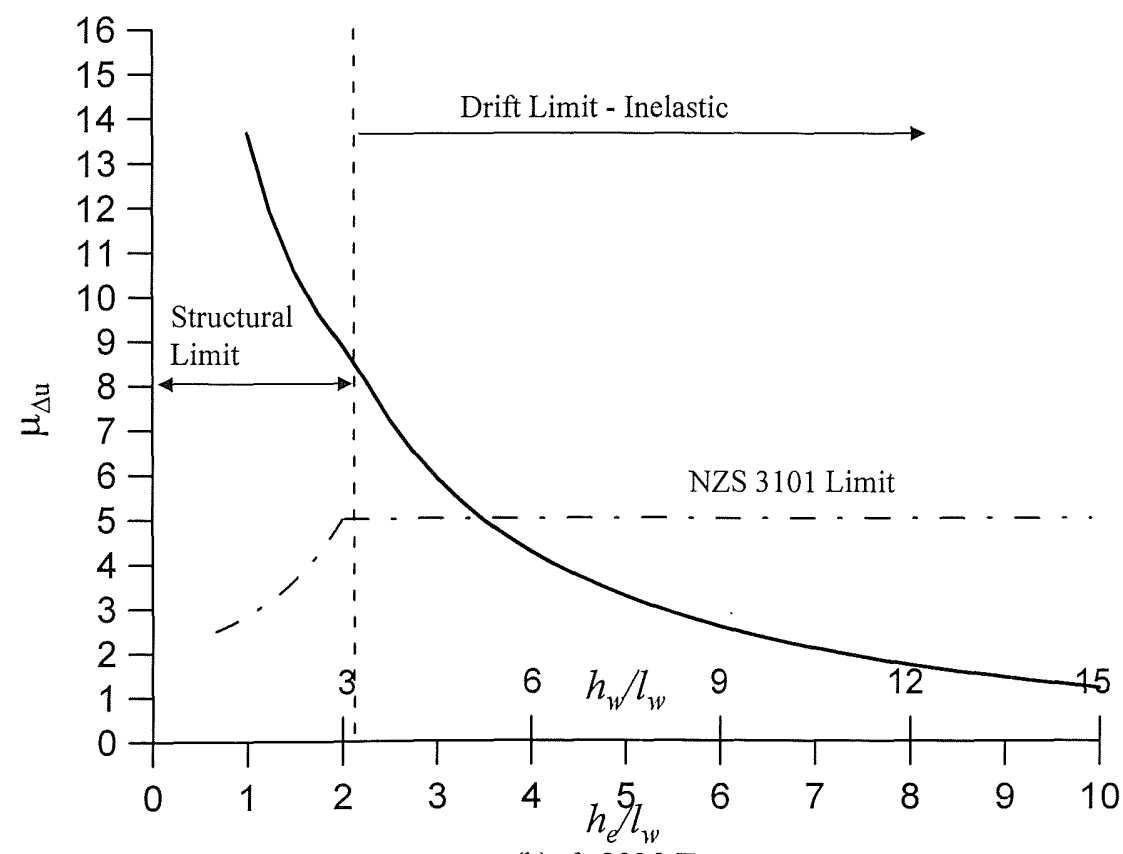

(b) $f_{y}=300 \mathrm{MPa}$

FIGURE 9 Maximum available ductility capacity related to aspect ratio, drift limit $=2.5 \%$ 


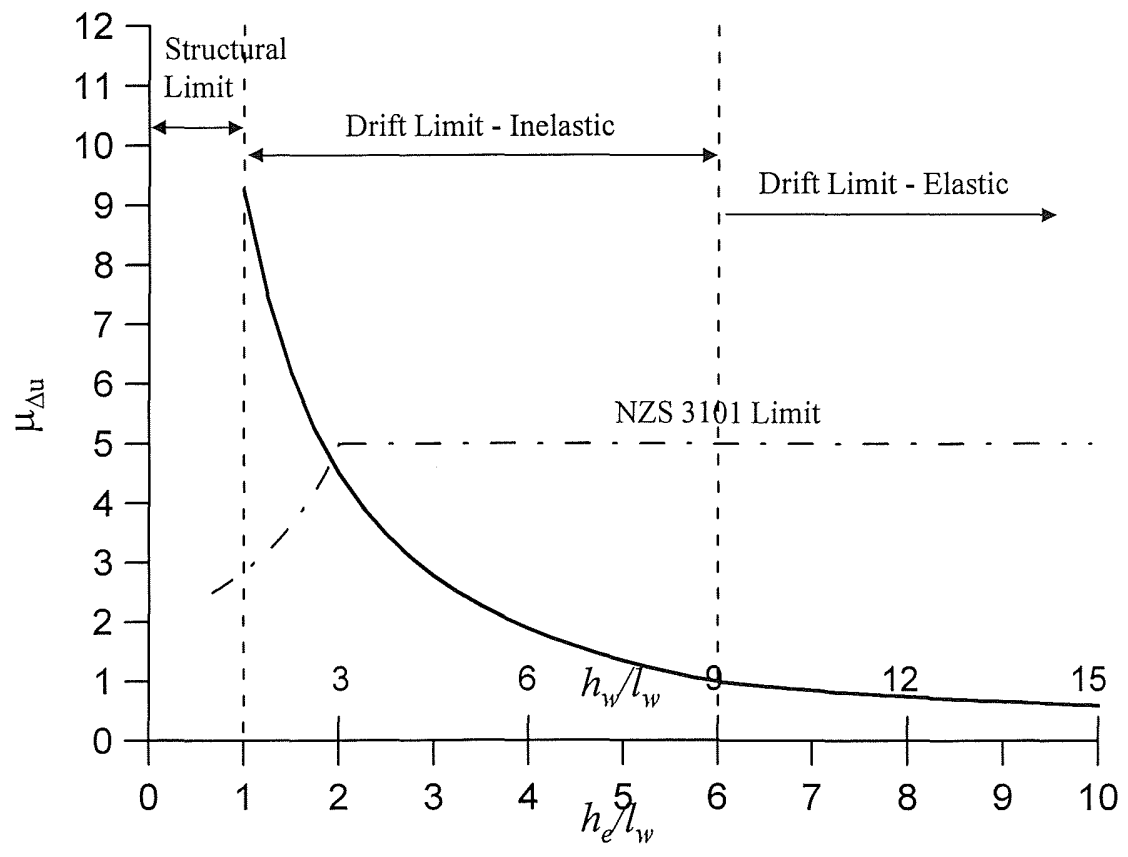

(a) $f_{y}=450 \mathrm{MPa}$

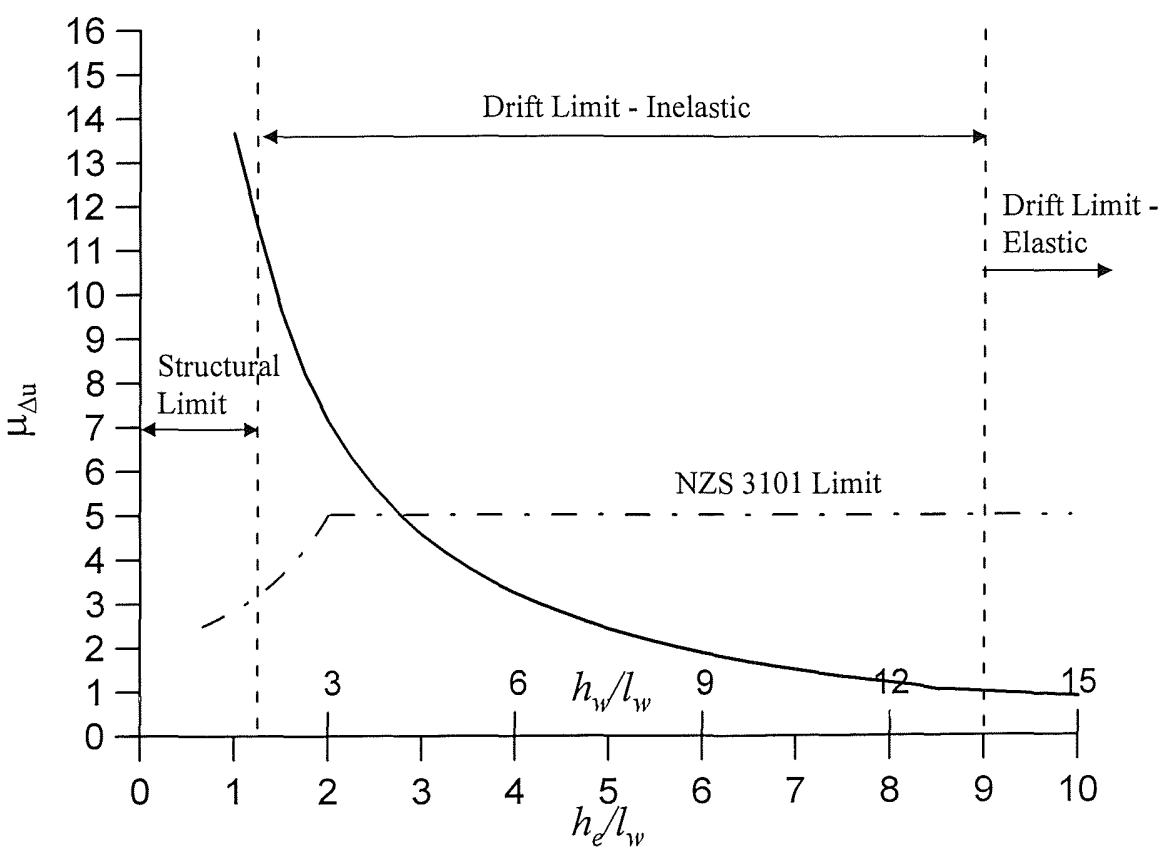

(b) $f_{y}=300 \mathrm{MPa}$

FIGURE 10 Maximum available ductility capacity related to aspect ratio, drift limit $=2 \%$ 


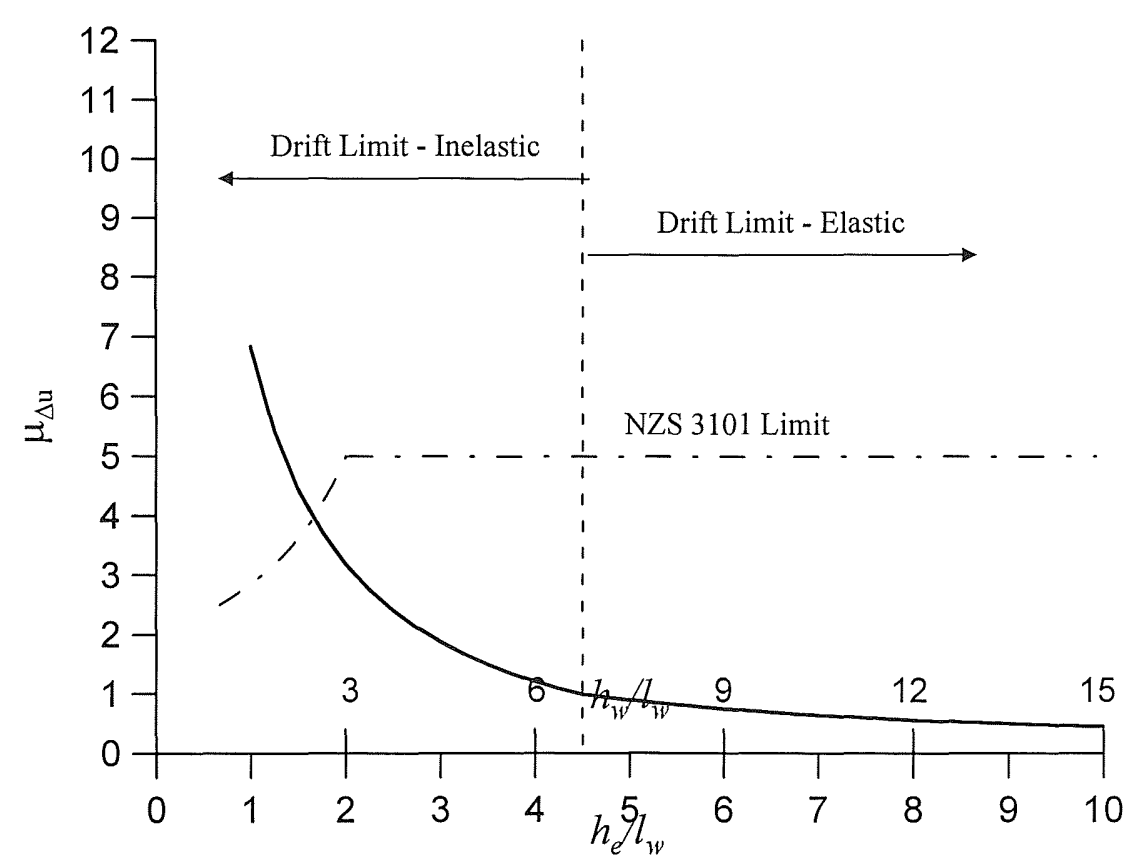

(a) $f_{y}=450 \mathrm{MPa}$

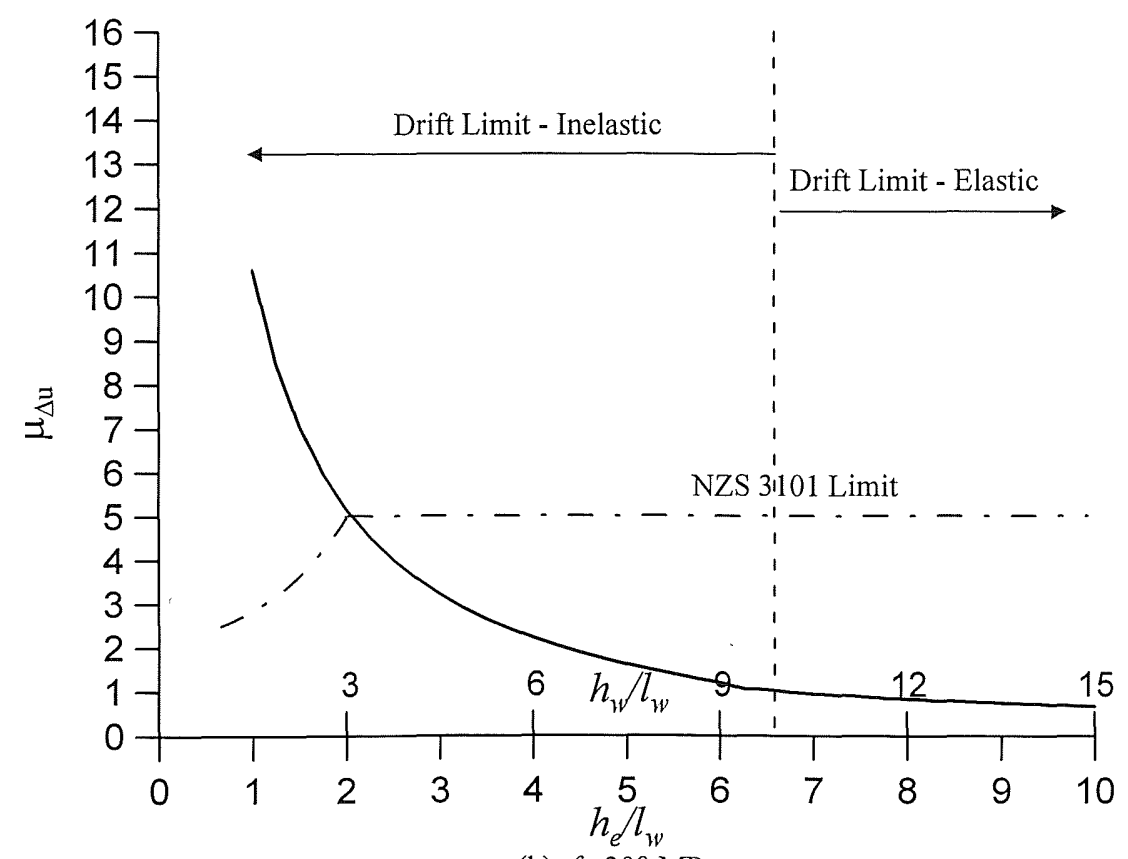

(b) $f_{y}=300 \mathrm{MPa}$ 
consequence it is possible to define the yield curvature as a function of wall length alone, for a given steel yield stress. Serviceability and ultimate curvatures depend only on the wall length.

2. The consequence of wall yield curvature (and hence yield displacement) being inversely proportional to wall length is that structures containing walls of different length cannot be designed such that the walls yield simultaneously. Also, wall design strength should be allocated in proportion to $\ell_{w}^{2}$ rather than $\ell_{w}^{3}$ as is currently done. A further consequence is that structural ductility capacity will be less than that of the longest wall, when walls with different length contribute to seismic resistance in a given direction.

3. Wall displacement ductility capacity reduces with aspect ratio. For walls reinforced with high strength reinforcement, the ductility capacity may be less than implied by NZS3101. Walls with lower grade reinforcement will have displacement ductility capacity exceeding the code value of $\mu_{\Delta}=5$. There is a case to be made for using different design ductility factors for walls with different yield strength.

4. Simple calculations based on the limit states curvatures indicate that the NZS4203 drift limits will govern for design of walls of of even very low aspect ratio. Slender cantilever walls with higher grade longitudinal reinforcement of aspect ratio $h_{w} / \ell_{w}>6.5$ must remain elastic to avoid violating the code drift limit of $\theta$ $=0.015$. Walls with aspect ratio $h_{w} / \ell_{w} \geq 3$ will generally need to be designed for displacement ductility factors less than the code value of $\mu_{\Delta}=5$. For such walls there is no advantage to the use of higher strength longitudinal reinforcement.

It should be noted that these conclusions only relate to rectangular cantilever walls. When the walls are combined with frames, reduced drifts will be developed in the critical upper stories. However, when realistic stiffnesses are used for estimating drifts of frame members, these will also often be found to be restricted by code drift limits.

The information provided in this paper may be of some use in determining appropriate ductility factors for wall design. However, the general limitation imposed by code drift limits indicates that a displacement based design approach [8], directly designing to achieve code drift limits may be appropriate in many cases.

\section{ACKNOWLEDGEMENTS}

Financial assistance from the Earthquake Commission through its Distinguished Earthquake Research Fellowship is gratefully acknowledged.

\section{REFERENCES}

1. Paulay, T. and Priestley, M.J.N., (1993) Seismic Design of Concrete \& Masonry Structures, John Wiley \& Sons, New York, 744 pages.

2. Priestley, M.J.N., (1993) Myths \& Fallacies in Earthquake Engineering -- Conflicts Between Design \& Reality, Bulletin NZNSEE, Vol. 26, No. 3, September, pp 329-341.

3. Priestley, M.J.N., Seible, F. and Calvi, E.M., (1996) Seismic Design \& Retrofit of Bridges, John Wiley \& Sons, New York, 686 pages.

4. SANZ -- NZS4203:1993, Code of Practice for General Structural Design and Design Loadings for Buildings, Standards Association of New Zealand, Wellington.

5. SANZ -- NZS3101:1995, Concrete Structures Standard (Parts 1 \& 2), Standards Association of New Zealand, Wellington.

6. King, D., Priestley, M.J.N. and Park, R., (1986) Computer Programs for Concrete Column Design, Research Report 86/12, Department of Civil Engineering, University of Canterbury, New Zealand, May.

7. Paulay, T., (1997) A Review of Code Provision for Torsional Seismic Effects in Buildings, Bulletin NZNSEE, Vol. 30 No. 3, September, pp 252-263.

8. Priestley, M.J.N. and Calvi, G.M., (1997) Concepts and Procedures for Displacement-Based Design and Assessment, Bled, Slovenia, Proceedings of the Workshop on Seismic Design Methodologies for the Next Generation of Codes, June 24. 